\title{
Unnoticed arrival of two dipteran species in Austria: the synanthropic moth fly Clogmia albipunctata (Williston, 1893) and the parasitic bird louse fly Ornithoica turdi (Olivier in Latreille, 1811)
}

\author{
Carina Zittra ${ }^{1,2}$ - Ellen R. Schoener ${ }^{1} \cdot$ Rüdiger Wagner $^{3} \cdot$ Mike Heddergott $^{4} \cdot$ Georg G. Duscher $^{1}$. \\ Hans-Peter Fuehrer ${ }^{1}$ (D)
}

Received: 16 January 2019 / Accepted: 22 November 2019 / Published online: 13 December 2019

(C) The Author(s) 2019

\begin{abstract}
In the framework of a mosquito-monitoring program conducted from 2014 to 2018, non-culicid dipteran bycatch was identified to species-level with a focus on Diptera of medical and veterinary importance as part of a biodiversity initiative and barcoding project ("Austrian Barcode of Life"). Two species hitherto not known from Austria, the regularly sampled synanthropic moth fly Clogmia albipunctata (Psychodidae) and a single specimen of the louse fly Ornithoica turdi (Hippoboscidae), were collected in Vienna and Lower Austria. We confirmed identification results using a barcoding approach and provide the first reference sequence for $O$. turdi.
\end{abstract}

Keywords Alien species $\cdot$ Health threat $\cdot$ Hippoboscidae $\cdot$ Psychodidae

\section{Introduction}

Drain flies or moth flies (Diptera: Psychodidae) are small- to medium-sized non-biting midges comprising around 3000 species worldwide. Clogmia albipunctata, also known as the "bathroom fly" is a near-cosmopolitan and synanthropic species of tropical origin (Boumans et al. 2009). It is commonly found in bathrooms, kitchens, sewers, and sewage treatment plants and in water-filled tree holes in the tropics, Slovakia, and the USA (Oboňa and Ježek 2012a, b) where the larvae feed as scrapers of biofilm and shredders of organic material (Boumans et al. 2009). The species spread in Northern and Central Europe in the past decades and is currently widely

Section Editor: Douglas D. Colwell

Hans-Peter Fuehrer

hans-peter.fuehrer@vetmeduni.ac.at

1 Department of Pathobiology, Institute of Parasitology, University of Veterinary Medicine, Veterinaerplatz 1, 1210 Vienna, Austria

2 Department of Limnology and Bio-Oceanography, University of Vienna, Althanstraße 14, 1090 Vienna, Austria

3 Universität Kassel FB 10, Zoologie, Heinrich-Plett-Straße 40, 34132 Kassel, Germany

4 Musée National d'Histoire Naturelle, 25 rue Münster, 2160 Luxembourg, Luxembourg distributed in anthropogenic habitats in tropical and temperate regions all over the world. This taxon is mostly considered a mechanical vector and indicator of poor hygiene standards, especially in hospitals, but was also found to be the cause of nasopharyngeal, intestinal and urinary myiasis in humans. The first European record was reported from Barcelona, Spain (Tonnoir 1920), under the synonym Telmatoscopus meridionalis (Eaton, 1894), while the distribution of this taxon was since then characterized as ranging worldwide between $40^{\circ} \mathrm{S}$ and $42^{\circ} \mathrm{N}$ (Vaillant 1971-1983). Since then, $C$. albipuntata was recorded in Belgium, Croatia, the Czech Republic, France, Germany, Greece, Italy incl. Sardinia, Karelian Russia, London (UK), Luxembourg, the Netherlands, Slovakia, Slovenia, Switzerland, and Spain (Ježek and Goutner 1995; Werner 1997; Ježek 2002; Withers 2005; Boumans et al. 2009; Wagner 2011; Oboňa and Ježek 2012a, b; Faulde and Spiesberger 2013; Kvifte et al. 2013; Humala and Polevoi 2015; Sivell and Irwin 2016).

The larval development of Psychodidae encompasses the egg, four larval instars, and the pupal and the adult stage and is dependent both on temperature and nutrient content (Boumans et al. 2009). Clogmia albipunctata females lay up to 300 eggs in moist substrate (von der Dunk 2011) and may complete its lifecycle within 17 days at temperatures ranging between 20 and $26^{\circ} \mathrm{C}$; adults live up to 10 days (Vaillant 1971). While one other group of Psychodidae, namely 
Table 1 Sampling date, storage conditions, sampling method, and locality of specimens of Ornithoica turdi and Clogmia albipunctata (V Vienna, LA Lower Austria)

\begin{tabular}{lllllllll}
\hline ID & Taxon & Sampling date & Sampling site & Province & Longitude & Latitude & Sampling method & Storage conditions \\
\hline D211 & O. turdi & 19.08 .2014 & 11th district Vienna & V & 48.176631 & 16.429126 & Carbon dioxide trap & EtoH, $-20{ }^{\circ} \mathrm{C}$ \\
D171 & C. albipunctata & 02.08 .2017 & 18th district Vienna & V & 48.235873 & 16.335558 & Carbon dioxide trap EtoH, $-20{ }^{\circ} \mathrm{C}$ \\
D174 & C. albipunctata & 04.09 .2017 & Strasshof an der Nordbahn & LA & 48.321225 & 16.671698 & Aspirator & EtoH, $-20{ }^{\circ} \mathrm{C}$ \\
D173 & C. albipunctata & 01.10 .2017 & Korneuburg & LA & 48.345079 & 16.334732 & Manual catch & EtoH, $-20{ }^{\circ} \mathrm{C}$ \\
D169 & C. albipunctata & 06.11 .2017 & Prottes & LA & 48.387095 & 16.736473 & Aspirator & $-20{ }^{\circ} \mathrm{C}$ \\
D167 & C. albipunctata & 23.01 .2018 & Korneuburg & LA & 48.345079 & 16.334732 & Manual catch & $-20{ }^{\circ} \mathrm{C}$ \\
D170 & C. albipunctata & 23.01 .2018 & Korneuburg & LA & 48.345079 & 16.334732 & Manual catch & $-20{ }^{\circ} \mathrm{C}$ \\
D168 & C. albipunctata & 01.05 .2018 & Jedenspeigen & LA & 48.496363 & 16.875892 & Manual & $-20{ }^{\circ} \mathrm{C}$ \\
D212 & C. albipunctata & 27.08 .2018 & Korneuburg & LA & 48.345079 & 16.334732 & Manual catch & EtoH, $-20{ }^{\circ} \mathrm{C}$ \\
D213 & C. albipunctata & 27.08 .2018 & Korneuburg & LA & 48.345079 & 16.334732 & Manual catch & EtoH, $-20{ }^{\circ} \mathrm{C}$ \\
D214 & C. albipunctata & 27.08 .2018 & Korneuburg & LA & 48.345079 & 16.334732 & Manual catch & EtoH, $-20{ }^{\circ} \mathrm{C}$ \\
D215 & C. albipunctata & 03.09 .2018 & Korneuburg & LA & 48.345079 & 16.334732 & Manual catch & EtoH, $-20{ }^{\circ} \mathrm{C}$ \\
D216 & C. albipunctata & 03.09 .2018 & Korneuburg & LA & 48.345079 & 16.334732 & Manual catch & EtoH, $-20{ }^{\circ} \mathrm{C}$ \\
D217 & C. albipunctata & 15.09 .2018 & Korneuburg & LA & 48.345079 & 16.334732 & Manual catch & EtoH, $-20{ }^{\circ} \mathrm{C}$ \\
\hline
\end{tabular}

Phlebotominae, are vectors of the medically important protozoan Leishmania, C. albipunctata is mainly of economic importance as it can occur in large numbers in synanthropic habitats and is mainly considered nuisance pests. However, intestinal and urinary myiasis caused by $C$. albipunctata has been reported with several cases worldwide.

Urinary myiasis was documented twice from Egypt (ElBadry et al. 2014; El-Dib et al. 2017), once from the Palestinian Territories (Hjaija et al. 2018), and once from India (Sarkar et al. 2018). Intestinal myiasis was reported twice from Malaysia (Mokhtar et al. 2016; Smith and Thomas 1979), once from Japan (Tokunaga 1953), and once from Taiwan (Tu et al. 2007). Furthermore, nasopharyngeal myiasis in man was rarely reported from Africa (Mohammed and Smith 1976, Nevill et al. 1970).

Investigations of the bacterial colonization of C. albipunctata have demonstrated the potential to act as a mechanical vector of pathogens associated with nosocomial infections (Faulde and Spiesberger 2013). Clogmia albipunctata was seen several times in Austria, for example, in Lower Austria in August 2012 and years later in Upper Austria in September 2016 (cf. https:// diptera.info/). Distribution and abundance data on this species in Austria are still limited. Our records and the first collected voucher specimens of this taxon contribute to the European dispersal of this species, but distribution, habitat preferences, and phenology in natural and man-made habitats in Austria as well as hospital infestations remain unknown and need to be assessed.

Hippoboscidae are robust and dorsoventrally flattened ectoparasites with a length ranging from 1.5 to $12.0 \mathrm{~mm}$ (Maa and Peterson, 1987). Worldwide, more than 21 genera comprising about 215 species are known, with the highest diversity in tropical and subtropical regions, while in the Nearctic region, about 13 genera containing about 31 species were recorded so far (Kock 2000, Maa and Peterson, 1987). The louse fly $O$. turdi (Latreille, 1812) is widely distributed in the Afrotropical and the Western Palearctic region (Maa 1969). This polyxenous ectoparasite had been found on a wide range of bird species among more than 57 avian genera of the orders Passeriformes, Falconiformes, Coraciiformes, Cuculiformes, and Strigiformes (cf. Maa 1969; Trilar \& Krčmar, 2005). In Europe, O. turdi was mainly recorded on Passeriformes and once on a strigiform bird (Droz and Haenni, 2011). Although the species is known in bordering counties, e.g., in Germany, since 1990 (Kock 2000, Heddergott \& Müller 2008) and in Switzerland since 2007, where it was collected on migrant Common firecrest Regulus ignicappilus (Droz and Haenni, 2011), it had not been found in Austria so far.

\section{Material and methods}

The framing mosquito-monitoring project used a standardized sampling scheme across Eastern Austria based on carbon dioxide baited Biogents Sentinel (Biogents®) mosquito traps (Zittra et al. 2016). The collected samples, including bycatch, were stored at $-20{ }^{\circ} \mathrm{C}$; bycatch was morphologically identified in the framework of the biodiversity initiative and barcoding project "Austrian Barcode of Life." We focused on Diptera of medical and veterinary importance, and among these, we chose to work with small families first to expedite progress. Specimens of $C$. albipunctata were collected rarely as bycatch but more frequently in-house, while only a single specimen of $O$. turd $i$ was collected using a mosquito trap. Species were identified by morphology and afterwards species identification was confirmed by analysis of the mitochondrial cytochrome oxidase subunit I gene (CO1): Genomic DNA 


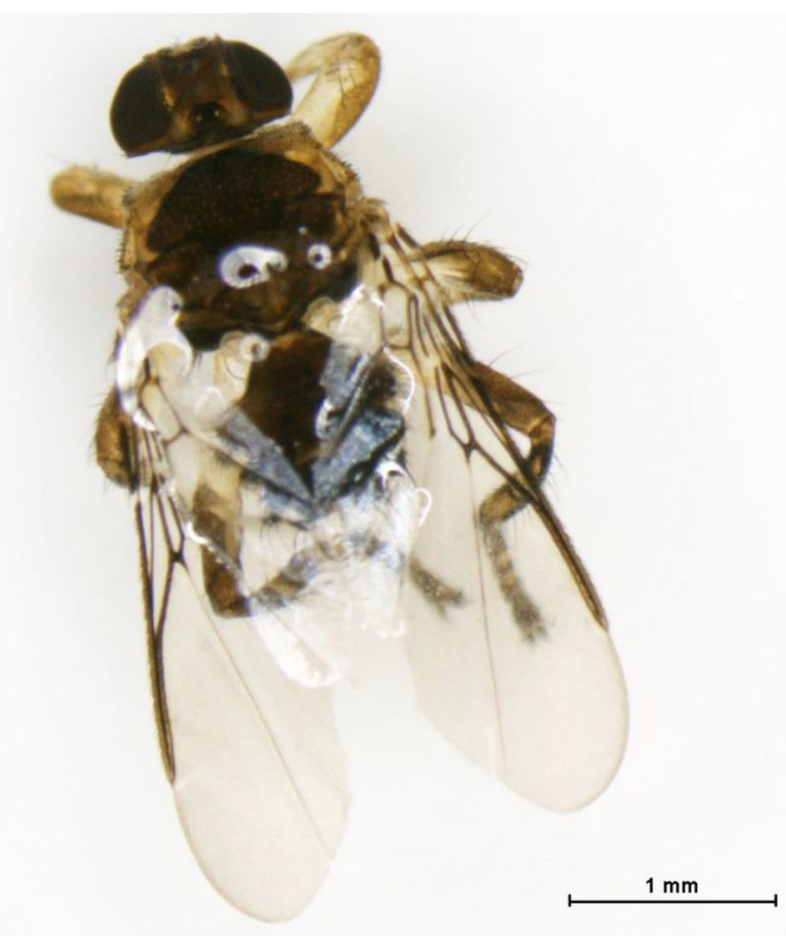

Fig. 1 Single specimen of Ornithoica turdi (Diptera: Hippoboscidae), collected in Vienna in 2014

was extracted from three legs of each specimen using the DNeasy ${ }^{\mathrm{TM}}$ Blood and Tissue Kit (Qiagen, Hilden, Germany) according to the manufacturer's protocol. Amplification of a $\sim 700$-bp-long mtCO1 fragment was achieved using barcode primers LepF1 and LepR1 as well as LCO1490 and HC02198 in standard PCR protocols (Folmer et al. 1994, Hebert et al. 2004). Afterwards, purified PCR products were sequenced by a commercial company (LGC Genomics GmbH, Germany).

\section{Results and discussion}

Between September 2017 and September 2018, 12 females of C. albipunctata were collected indoors at three locations in the district of Gänserndorf, and at a single location in the district of Korneuburg. In Vienna, a single individual of C. albipunctata was caught outdoors, using a carbon dioxide baited trap, in August 2017 in the 18th district of Vienna (Table 1). Whereas C. albipunctata was collected regularly at these sampling sites, only a single specimen of $O$. turd $i$ was recorded outdoors in the 14th district of Vienna in August 2014 (Fig. 1).

In the case of $C$. albipunctata, molecular identification verified morphological identification of all specimens, all obtained sequences were identical (GenBank ${ }^{\circledR}$ accession number MK234696). In contrast, reference sequences were not available for $O$. turdi and we furnish the first COI sequence of this species (GenBank® accession number MK234697).
Clogmia albipunctata is a non-native species of tropical origin (Boumans et al. 2009), expanding its native range far to the North, transported intercontinentally by man with organic material, e.g., vegetables (Wagner et al. 2008). This taxon was reported to breed in natural tree holes in Central Europe but it is still not considered to be a biodiversity hazard at present in Austria, due to their inability to overwinter in this specialized habitats (Ježek et al. 2012; Oboňa and Ježek 2012a, b; Kvifte et al. 2013). Moreover, C. albipunctata is described as a year-round pest in hospitals and as a potential mechanical vector of bacterial pathogens especially of those associated with nosocomial infections, but this has not been observed in Austria so far. The regularly findings of C. albipunctata distributed across Lower Austria indicate a wide distribution in Austria, which should be noticed and observed vigilantly in future. However, distribution and abundance patterns of $O$. turdi in Austria are still unknown, as generally knowledge on Hippoboscidae is poor.

Acknowledgments We are grateful to the collectors of the specimens: Anja Joachim, Ira Orlicek, Bärbel Ruttkowski, and Walpurga WillePiazzai.

Funding information Open access funding provided by University of Veterinary Medicine Vienna. Financial support was partly provided by the Austrian Federal Ministry of Education, Science and Research via an ABOL (Austrian barcode of Life; http://www.abol.ac.at associated project within the framework of the "Hochschulraum-Strukturmittel" Funds.

\section{Compliance with ethical standards}

Conflict of interest The authors declare that there is no conflict of interest.

Open Access This article is licensed under a Creative Commons Attribution 4.0 International License, which permits use, sharing, adaptation, distribution and reproduction in any medium or format, as long as you give appropriate credit to the original author(s) and the source, provide a link to the Creative Commons licence, and indicate if changes were made. The images or other third party material in this article are included in the article's Creative Commons licence, unless indicated otherwise in a credit line to the material. If material is not included in the article's Creative Commons licence and your intended use is not permitted by statutory regulation or exceeds the permitted use, you will need to obtain permission directly from the copyright holder. To view a copy of this licence, visit http://creativecommons.org/licenses/by/4.0/.

\section{References}

Boumans L, Zimmer J-Y, Verheggen F (2009) First records of the 'bathroom mothmidge' Clogmia albipunctata, a conspicuous element of the Belgian fauna that went unnoticed (Diptera: Psychodidae). Phegea 37:153-160

Droz B, Haenni J-P (2011) Une mouche pupipare nouvelle pour la fauna de Suisse (Diptera: Hippoboscidae). Entomo Helv 4:59-63 
El-Badry AA, Salem HK, El-Aziz Edmardash Y (2014) Human urinary myiasis due to larvae of Clogmia (Telmatoscopus) albipunctata Williston (Diptera: Psychodidae) first report in Egypt. J Vector Borne Dis 51:247-249

El-Dib NA, El Wahab WMA, Hamdy DA, Ali MI (2017) Case report of human urinary myiasis caused by Clogmia albipunctata (Diptera: Psychodidae) with morphological description of larva and pupa. J Arthropod Borne Dis 11(4):533-538

Faulde M, Spiesberger M (2013) Role of the moth fly Clogmia albipunctata (Diptera: Psychodinae) as a mechanical vector of bacterial pathogens in German hospitals. J Hosp Infect 83:51-60

Folmer O, Black W, Hoeh W, Lutz R, Vrijenhoeck R (1994) DNA primers for amplifications of mitochondrial cytochrome $\mathrm{c}$ oxidase subunit I from diverse metazoan invertebrates. Mol Mar Biol Biotechnol 3:294-299

Hebert PDN, Penton EH, Burns JM, Janzen DH, Hallwachs W (2004) Ten species in one: DNA barcoding reveals cryptic diversity in the neotropical skipper butterfly Astraptes fulgerator. PNAS 101(41): $14812-14817$

Heddergott M, Müller F (2008) Erneuter Nachweis von Ornithoica turdi (Latreille, 1812) in Deutschland (Diptera: Hippoboscidae). Studia dipterol 15:297-300

Hjaija D, Sawalha SS, Sami Amr Z, Katbeh-Bader A, Hasson RAH (2018) Urinary myiasis caused by Clogmia albipunctata from the Palestinian territories. Bulletin de la Société de Pathologie Exotique 111(3):148-151

Humala A, Polevoi A (2015) Находки редких и примечательных видов насекомых (Insecta) на территории Карелии. Transactions of KarRC RAS 6:19-46

Ježek J, Lukáš J, Kvifte GM, Oboňa J (2012) New faunistic records of non-biting moth flies (Diptera: Psychodidae) from the Czech Republic and Slovakia. Klapalekiana 48:121-126

Ježek J (2002) The first account of Slovenian moth flies (Psychodidae, Diptera). J Nat Mus, Nat Hist Ser 171:131-175

Ježek J, Goutner V (1995) Psychodidae (Diptera) of Greece. Acta Musei Nationalis Pragae 50B (1994): 107-124

Kock D (2000) Ornithoica turdi (LATREILLE 1812) neu in der Fauna Deutschlands und ihre Phänologie in der westlichen Paläarktis (Insecta: Diptera: Hippoboscidae). Senckenb Biol 80(1/2):155-158

Kvifte GM, Ivković M, Klarić A (2013) New records of moth flies (Diptera: Psychodidae) from Croatia, with the description of Berdeniella keroveci sp. nov. Zootaxa 3737:057-067

Maa TC (1969) Studies in Hippoboscidae (Diptera). Part 2. Pac Insects Monogr 20:1-312

Maa TC, BV Peterson. (1987) Hippoboscidae. In: Mc-Alpine, J. F., B. V. Peterson, G. E. Shewell, Teskey HJ, Vockeroth, JR, Wood DM, editors. eds. Manual of nearctic Diptera. Volume 2: Quebec, Canada Canadian Government Publishing Centre. p. 1271-1281

Mohammed N, Smith KG (1976) Nasopharyngeal myiasis in man caused by larve of Clogmia (=Telmetoscopus) albipunctatus Williston (Psychodidae, Dipt.) Trans R Soc Trop Med Hyg 70(1):91

Mokhtar AS, Braima KA, Peng Chin H, Jeffery J, Mohd Zain SN, Rohela M, Lau YL, Jamaiah I, Wilson JJ, Abdul-Aziz NM (2016) Intestinal myiasis in a Malaysian patient caused by larvae of Clogmia albipunctatus (Diptera: Psychodidae). J Med Entomol 53(4): 957-960

Nevill EM, BAsson PA, Schroonraad JH, Swanpoel KA (1970) A case of nasal myiasis caused by the larvae of Telmatoscopus albipunctatus
(Williston) 1893 (Diptera: Psychodidae). Trop Dis Bull 67(4):400 402

Oboňa J, Ježek J (2012a) First records of dendrolimnetic moth flies (Diptera: Psychodidae) from Slovakia. Klapalekiana. 48:279-287

Oboňa J, Ježek J (2012b) Additions to the range expansion of the invasive moth midge Clogmia albipunctata (Williston, 1893) in Slovakia (Diptera: Psychodidae). Folia faunistica Slovaca 17(4):387-391

Sarkar SD, Mandal DM, Banerjee D (2018) First report of drain fly, Telmatoscopus albipunctata (Vaillant, 1972) (Diptera: Psychodidae): causative agent of a rare urinary myiasis from India. JMSCR 6(8):70-74

Sivell D, Irwin T (2016) Clogmia albipunctata in London. Dipterists Digest Second Series 23:111-115

Smith KG, Thomas V (1979) Intestinal myiasis in man caused by larvae of Clogmia (= Telmatoscopus) albipunctatus Williston (Psychodidae, Diptera). Trans R Soc Trop Med Hyg 73(3):349-350

Tokunaga M (1953) Moth-Flies that Cause Myiasis in Man in Japan. Medical Entomology and Zoology 4 (3-4):101-107

Tonnoir AL (1920) Notes sur quelques Psychodidae africains. Revue zoologique africaine. 8:127-147

Trilar T, Krčmar S (2005) Contribution to the knowledge of louse flies of Croatia (Diptera: Hippoboscidae). Nat Croat 14(2):131-140

Tu WC, Chen HC, Chen KM, Tang LC, Lai SC (2007) Intestinal myiasis caused by larvae of Telmatoscopus albipunctatus in a Taiwanese man. J Clin Gastroenterol 41:400-402

Vaillant F (1971-1983): 9d. Psychodidae - Psychodinae. In: LINDNER E. (ed.): Die Fliegen der palaearktischen Region. E. Schweizerbart'sche Verlagsbuchhandlung (Nägele und Obermiller), Stuttgart. Vols. 287 (1971): 1-48; 291 (1972): 49-78; 292 (1972): 79-108; 305 (1974): 109-142; 310 (1975): 143-182; 313 (1977): 183-206; 317 (1978): 207-238; 320 (1979): 239-270; 326 (1981): 271-310; 328 (1983): 311-357

Vaillant F (1971) Psychodidae - Psychodinae. In: Lindner, E. (Ed.) Die Fliegen der Palearktischen Region. Lieferung 287. E. Schweizerbart'sche Verlagsbuchhandlung, Stuttgart.pp. 1-48

Von der Dunk (2011) Drei synanthrope Neozoen. Berichte des Kreises Nürnberger Entomologen. 27/3: 149-154

Wagner R (2011) Fauna Europaea: Psychodidae. In: JONG H. (ed.): Fauna Europaea: Diptera Nematocera. Fauna Europaea version 2.4. Available on: http://www.faunaeur.org (accessed 27 January 2011)

Wagner R, Barták M, Borkent A, Courtney G, Goddeeris B et al (2008) Global diversity of dipteran families (Insecta Diptera) in freshwater (excluding Simuliidae, Culicidae, Chironomidae, Tipulidae and Tabanidae). Hydrobiologia 595:489-519

Werner D (1997) Studies on some moth flies (Diptera: Psychodidae) with the first record of Clogmia albipunctata in central Europe. Entomol News 108:273-282

Withers P (2005) New records of Psychodidae (Diptera) for Switzerland. Rev Suisse Zool 112:183-188

Zittra C, Flechl E, Kothmayer M, Vitecek S, Rossiter H, Zechmeister T, Fuehrer HP (2016) Ecological characterization and molecular differentiation of Culex pipiens complex taxa and Culex torrentium in eastern Austria. Parasit Vectors 9:197. https://doi.org/10.1186/ s13071-016-1495-4

Publisher's note Springer Nature remains neutral with regard to jurisdictional claims in published maps and institutional affiliations. 